\title{
BMJ Open Walk, Talk and Listen: a pilot randomised controlled trial targeting functional fitness and loneliness in older adults with hearing loss
}

\author{
Charlotte A Jones, ${ }^{1}$ Jodi Siever, ${ }^{1}$ Kate Knuff, ${ }^{1}$ Colin Van Bergen, ${ }^{2}$ Paul Mick, ${ }^{1}$ \\ Jonathan Little, ${ }^{3}$ Gareth Jones, ${ }^{4}$ Mary-Ann Murphy, ${ }^{5}$ Donna Kurtz, ${ }^{6}$ Harry Miller ${ }^{1}$
}

To cite: Jones CA, Siever J, Knuff K, et al. Walk, Talk and Listen: a pilot randomised controlled trial targeting functional fitness and Ioneliness in older adults with hearing loss. BMJ Open 2019;9:e026169. doi:10.1136/ bmjopen-2018-026169

- Prepublication history and additional material for this paper are available online. To view these files, please visit the journal online (http://dx.doi. org/10.1136/bmjopen-2018026169).

Received 20 August 2018 Revised 11 February 2019 Accepted 13 February 2019

Check for updates

(C) Author(s) (or their employer(s)) 2019. Re-use permitted under CC BY-NC. No commercial re-use. See rights and permissions. Published by BMJ.

For numbered affiliations see end of article.

Correspondence to

Dr Charlotte A Jones;

charlotte.jones@ubc.ca

\section{ABSTRACT}

Background Age-related hearing loss $(\mathrm{HL})$ is a prevalent disability associated with loneliness, isolation, declines in cognitive and physical function and premature mortality. Group audiological rehabilitation (GAR) and hearing technologies address communication and cognitive decline. However, the relationship between loneliness, physical function and GAR among older adults with HL has not been studied.

Objectives Explore the impact of a group exercise and socialisation/health education intervention and GAR on physical function and loneliness among older adults with HL.

Trial design A Young Men's Christian Association (YMCA)based, 10-week, single-blind, pilot randomised controlled trial (RCT).

Participants Ambulatory adults aged 65 years or older with self-reported $\mathrm{HL}$.

Interventions Seventy-one participants were screened. Thirty-five were randomised to intervention (strength and resistance exercise, socialisation/health education) and GAR (hearing education, communication strategies, psychosocial support) or control $(n=31)$ : GAR only.

Outcomes Ninety-five per cent of eligible participants were randomised. GAR and exercise adherence rates were $80 \%$ and $85 \%$, respectively. $88 \%$ of participants completed the study. Intervention group functional fitness improved significantly (gait speed: effect size: $0.57,30 \mathrm{~s}$ Sit to Stand Test: effect size: 0.53). Significant improvements in emotional and social loneliness (effect size: 1.16) and hearing-related quality of life (effect size: 0.76 ) were related to GAR attendance and poorer baseline hearingrelated quality of life. Forty-two per cent of participants increased social contacts outside the study.

Discussion Walk, Talk and Listen was feasible and acceptable. Exercise and socialisation/health education improved loneliness and key fitness measures but provided no additional benefit to GAR only for loneliness. This is the first preliminary evidence about the benefits of exercise on fitness and GAR on loneliness among older adults with $\mathrm{HL}$.

Implications This pilot trial provides key information on the sample size required for a larger, longer term RCT to determine the enduring effects of this holistic intervention addressing the negative psychosocial and musculoskeletal downstream effects of HL among older adults.
Strengths and limitations of this study

- First study to examine the effects of exercise intervention and auditory rehabilitation on functional fitness and loneliness among older adults with hearing loss.

- Fifty-seven per cent of participants are male: unusual for a community exercise programme.

- This is an exploratory single-blind pilot randomised controlled trial

There is not a control group with no intervention.

\section{BACKGROUND}

Hearing loss (HL) is a prevalent and under-recognised disability that is associated with significant psychosocial and physical challenges. Large surveys ${ }^{1}{ }^{2}$ indicate that between $65 \%$ and $77 \%$ of North American adults aged 60-79 have audiometrically measured HL.

Untreated HL is associated with increased rates of loneliness, social isolation, ${ }^{34}$ depression, accelerated cognitive decline, declines in physical function, gait speed, balance, frailty, increased falls, hospitalisations and premature mortality. ${ }^{5}$

These downstream effects of HL are inter-related. Numerous theories exist regarding the mechanism of these associations. One theory suggests that increased cognitive energy is used to comprehend sound/language, leaving less cognitive reserve for complicated tasks such as memory, social interaction and walking. ${ }^{5}$ Work is ongoing in this area. ${ }^{67}$ Another theory posits that HL-related social isolation and loneliness are linked to the cognitive decline, depression, impaired physical function, falls and mortality among older adults. ${ }^{489}$

Social isolation is an objective measure of lack of contact/interactions with others, ${ }^{10}$ while loneliness is a subjective feeling of the 
lack of meaningful social connections. ${ }^{11}$ Linked to HL-related decreases in social participation, loneliness has also been independently associated with depression, cognitive decline, reduced physical functioning and mortality (reviewed in refs 12 13).

Hearing technologies (hearing aids, assistive technologies and cochlear implants) and communication programmes (one on one or group auditory rehabilitation [GAR]) are the current approaches to treating HL. GAR programmes include education about hearing, hearing devices/technologies, enhancing communication skills and psychosocial support. ${ }^{14}$ Hearing technologies improve auditory function, cognitive decline, depression and loneliness. ${ }^{15-17}$ GAR improves objective measures of social participation (social isolation) ${ }^{18}$ and hearing-related quality of life; however, to our knowledge, no studies explore how GAR programmes impact loneliness or physical function among older adults with HL.

Group programmes for lonely/socially isolated older adults involving interactive shared activities (eg, social/ cultural, educational or physical activities), as opposed to independent activities (eg, reading or watching TV), improve quality of life, loneliness ${ }^{19-22}$ and in those that included exercise interventions, physical function and premature mortality. ${ }^{22} 23$

Since HL, loneliness and physical inactivity are inter-related and associated with multiple comorbidities, it is of interest to explore interventions that improve loneliness and physical function among older adults with HL. In this pilot randomised controlled trial (RCT), Walk, Talk and Listen (WTL), we begin to explore the impact of GAR on loneliness and physical function, and importantly, whether addition of an interactive/social group educational and physical strengthening intervention is of any additional benefit to older adults with HL.

\section{Objective}

Examine the feasibility and impact of a group exercise and socialisation/health education (SHE) intervention added to GAR on physical function, hearing-related quality of life and loneliness among older adults with HL.

\section{DESIGN AND METHODS}

\section{Patient and public involvement}

Twenty-eight older adults with HL participated in the design of the intervention for this clinical trial. ${ }^{24}$ WTL participants helped, by word of mouth, to recruit several other participants. WTL participants provided ongoing and end-of-study feedback and helped disseminate the trial results. One participant and the principle investigator continue to deliver GAR sessions twice a year in the local community.

\section{Trial protocol}

Detailed WTL methodology is reported elsewhere. ${ }^{25}$ Briefly, in partnership with the Young Men's Christian Association (YMCA) Okanagan, WTL was a 10-week prospective single-blind randomised controlled pilot trial of interactive GAR (control) versus GAR plus interactive SHE and strengthening exercises in community-dwelling, ambulatory older adults (age 65 or above) with self-reported $^{26}$ HL (ClinicalTrials.gov NCT02662192. Pre-results. Registered 14 January 2016). Participants were recruited over the two time periods preceding the trial (January to February 2016 and July to August 2016) through local newspaper ads, strategically placed posters and word of mouth. Potential participants contacting the trial centre underwent preliminary telephone eligibility assessment after the study was briefly described and verbal consent obtained. At the YMCA, eligible ${ }^{25}$ participants signed informed consent and underwent baseline (week 0 ) and follow-up (week 11) assessments completed by trained students and research team members. All procedures included groups of 10-20 participants and took place in a small, acoustically favourable meeting room and/or a small gym at the same YMCA site over a period of 10 weeks. One-hour control group GAR-only sessions occurred once a week. Intervention group 1-hour GAR sessions were followed by $60 \mathrm{~min}$ of exercise (strength, resistance and coordination training: $45 \mathrm{~min}$ ) and walking (outside or on indoor track: $15 \mathrm{~min}$ ). On their second weekly visit, intervention participants attended a 1-hour interactive SHE session ${ }^{25}$ followed by $60 \mathrm{~min}$ of exercise and walking. A certified YMCA trainer facilitated the exercise sessions. Participants were encouraged to walk between sessions and were provided a pedometer and tracking sheets to motivate them. At study end, control participants were offered the exercise programme and provided a pedometer. Trained students helped the principle investigator facilitate the GAR and SHE sessions. Interactive GAR sessions were guided by a modification of the The Group Rehabilitation Online Utility Pack (GROUP) programme ${ }^{27}$ and provided hearing education, goal setting and psychosocial and behaviour change exercises including mindfulness, acceptance of HL, assertiveness training, communication strategies, problem-solving, anticipatory and repair strategies. Participants were encouraged to review class handouts with their communication partners (spouse, significant other or friend). One 3-hour large-group communication partner session was held near the end of the study. The trial was conducted over two separate 10-week time periods (with different participants) to accommodate YMCA scheduling and allow for smaller participant groups.

\section{Feasibility and acceptability}

Feasibility, including recruitment strategies and rates, acceptability/willingness to be randomised, adverse events, GAR attendance rates, overall retention rates, and acceptability of the GAR and exercise components, was assessed at follow-up (end of study). A priori, it was decided that a definitive RCT would be feasible if at least 120 individuals contacted the pilot trial centre, $\geq 90 \%$ of eligible participants were randomised and $70 \%$ of those completed the study. The WTL intervention was 
acceptable if at least $85 \%$ of participants found the GAR, exercise and SHE sessions highly acceptable or acceptable.

\section{Participant-specific outcomes}

Demographic data were collected at baseline (week 0), and the remaining measures at baseline and follow-up (week 11).

Standard functional fitness outcomes included $30 \mathrm{~s}$ Chair Sit to Stand Test, ${ }^{28}$ gait speed: 6 min Walk Test, ${ }^{29}$ Timed Up and Go Test, ${ }^{29}$ One-Foot Balance Test, ${ }^{30}$ Grip Strength, ${ }^{31}$ Chair Sit and Reach Test $^{32}$ and the Back Scratch. ${ }^{33}$

Psychosocial measures included self-reported hearing-related quality of life or hearing handicap (Hearing Handicap Inventory for the Elderly [HHIE-25] $)^{26}$ and the Rand SF-36 ${ }^{34}$ (Short Form [general] quality of life measure) respectively, de Jong loneliness, ${ }^{35}$ social support (the Medical Outcomes Trial-Social Support Survey ${ }^{36}$ ) and depression (Geriatric Depression Scale ${ }^{37}$ ).

\section{GAR evaluation}

The international outcomes inventory-alternative interventions (IOI-AI ${ }^{38}$ and the modified Client Oriented Scale of Improvement (COSI) questionnaires ${ }^{39}$ were completed by all participants at follow-up. A follow-up evaluation questionnaire assessed the acceptability of the exercise and GAR sessions, acceptance and attitude about their HL, HL-related problem-solving, stress management and self-confidence in social situations.

\section{Sample size}

At least 23 people per group were needed to show a clinically meaningful increase in Sit to Stand of 2 or more ${ }^{40}$ : the primary fitness outcome. This was inflated by $20 \%$ to account for dropouts and ensured generation of a reliable SE, SD and 95\% CIs on the sample size required for a large RCT with this measure as the primary outcome. ${ }^{41}$

\section{Statistical methods}

Categorical data were expressed as frequency and percentage (eg, recruitment, adherence, overall retention rates). Continuous data were expressed as mean+SD or median and IQR (for non-normal data). Baseline data were compared between groups using a Fisher's exact test or independent samples t-test (Mann-Whitney U test where appropriate). Intention-to-treat analyses were conducted to examine change over time in functional fitness and psychosocial measures. Effect sizes (ES) ${ }^{42}$ and 95\% CIs for within-group changes and between-group differences are reported. Confounding and effect modification were examined using linear regression modelling with the change score as the dependent variable. GAR attendance was determined a priori as a potential confounding factor and HHIE-25 was included post hoc to account for the unanticipated baseline differences. All results are presented as intention to treat using the baseline observation carried forward to produce the most conservative results. Analyses were conducted in Stata S/E
V.15 (Stata [StataCorp. Stata Statistical Software: Release 15 , College Station, TX, USA: StataCorp]) and $\mathrm{p}<0.05$ was considered statistically significant.

\section{RESULTS}

\section{Feasibility}

The WTL Consolidated Standards of Reporting Trials diagram is shown in figure 1 . One hundred and thirty-seven individuals contacted the study centre, 119 completed the initial phone screen and 71 completed full eligibility screening. Ninety-six per cent of eligible participants $(n=69)$ were randomised $(n=66)$ and $88 \%$ of participants $(n=58)$ completed the study. GAR and exercise attendance rates were $80 \%$ and $85 \%$, respectively. There was one adverse event (fall with hip fracture) within the trial during an exercise session and two outside the study in control group participants (one fall with hip fracture, one foot infection). Primary reasons for ineligibility included too young (33\%) and no self-reported HL $(67 \%)$. Newspaper ads were the most successful recruitment strategy (74\%), followed by word of mouth (18\%) and community posters or social media (8\%) (data not tabled). The main reasons for withdrawal during enrolment $(\mathrm{n}=42)$ were time commitment $(50 \%)$ and inconvenient location $(24 \%)$.

\section{Baseline measures}

Among the 66 participants in the study, the mean age was 74.5 years, $57 \%$ were male, $94 \%$ Caucasian, $67 \%$ married/ common law, $64 \%$ had completed some college/university or above, $54 \%$ reported an annual household income above \$C50 000.00 and 88\% were retired. Ten participants used mobility or balance aids, just over half used hearing aids and 11 reported one or more falls in the previous 3 months. Groups did not differ on any functional fitness or psychosocial measure with the exception of the total HHIE-25 score (control median=56; intervention median=38; $\mathrm{p}=0.045)$. (table 1$)$

\section{Change in functional fitness and psychosocial measures}

After adjusting for baseline HHIE-25 imbalance, gait speed improved more in the intervention group compared with the control group by an average of 0.05 $\mathrm{m} / \mathrm{s}(95 \%$ CI 0.0 to $0.09 ; \mathrm{p}=0.046$; $\mathrm{ES}=0.57)$. Compared with the control group, intervention group Sit to Stand measures improved significantly more by an average of 1.0 Sit to Stand (95\% CI 0.1 to 2.0; $\mathrm{p}=0.037$; $\mathrm{ES}=0.53$ ). Back Scratch improved by an average of $4 \mathrm{~cm}$ more in the intervention group compared with the control group (95\% CI 0.2 to $7.7 ; \mathrm{p}=0.039 ; \mathrm{ES}=0.54$ ). The de Jong emotional loneliness subscale showed greater improvement in the control group: average difference in change of 0.6 (95\% CI 0.1 to $1.2 ; \mathrm{p}=0.043 ; \mathrm{ES}=-0.54)$. There were no significant differences for depression, social support or SF-36 measures (all $p>0.05$ ) (online supplementary file 1). (table 2) 


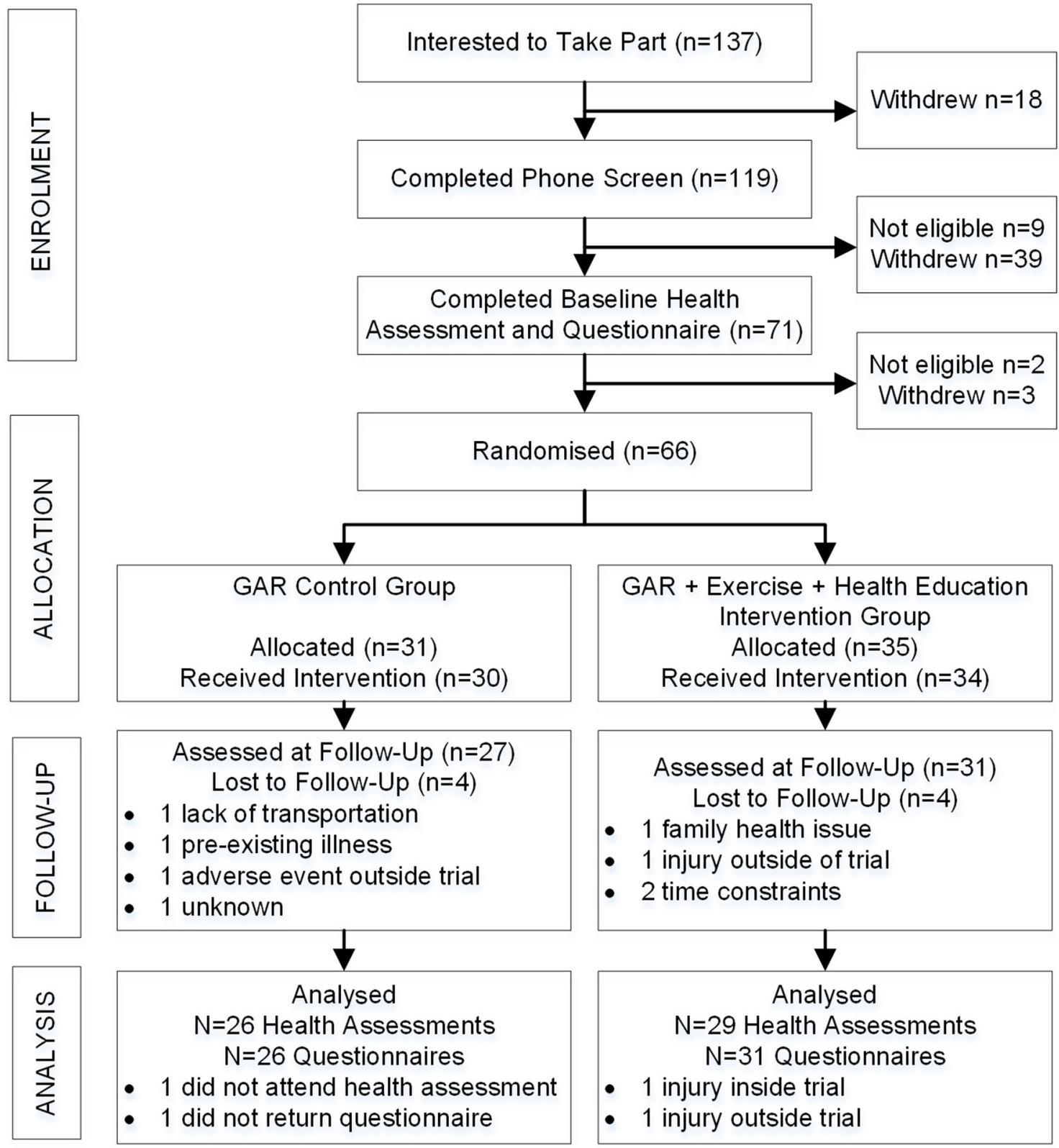

Figure 1 Participant time line: Consolidated Standards of Reporting Trials (CONSORT)-style flow chart. GAR, group auditory rehabilitation.

Improvements in HHIE-25 and de Jong loneliness were influenced by GAR attendance (table 3). Total, emotional and social HHIE-25 subscales showed significant improvement for those who attended $\geq 80 \%$ of GAR sessions: total: $95 \%$ CI -19.7 to $-2.6 ; \mathrm{p}=0.012$; $\mathrm{ES}=0.76$, emotional: $95 \%$ CI -11.0 to $-1.1 ; \mathrm{p}=0.018$; $\mathrm{ES}=0.71$, social: $95 \% \mathrm{CI}-9.5$ to $-0.8 ; \mathrm{p}=0.022 ; \mathrm{ES}=0.69$, regardless of group assignment. Similarly, those with $\geq 80 \%$ GAR attendance had a greater decrease in de Jong total (95\% CI -2.7 to $-0.9 ; \mathrm{p} \leq 0.001 ; \mathrm{ES}=1.16)$ and emotional loneliness (95\% CI -1.7 to -0.4 ; $\mathrm{p}=0.002 ; \mathrm{ES}=0.96)$.

\section{GAR evaluation}

At study end, participant responses to the seven IOI-AI questions (table 4) revealed that $67 \%$ of participants were using GAR communication strategies on a daily basis for at least 1 hour. The majority reported moderate or greater benefit from using GAR strategies, satisfaction with the GAR programme, improvement in participation restrictions (visiting friends/relatives less than desired) and improvement in activity limitations (difficulty hearing TV or speech). COSI results were favourable overall (online supplementary file 2). Participants reported slightly better or greater progress in their goals of improving "conversations with one or two or a group of people in a quiet environment' $(67 \%)$ or 'noisy' environment $(53 \%)$, half $(51 \%)$ felt less embarrassed or stupid and $42 \%$ increased the amount of their social contact (such as attending more social events, social situations or going out in public). 
Table 1 Baseline demographics, functional fitness and psychosocial measures, by group (control $n=31$; intervention $n=35$ ) and for the overall sample $(n=66)$

\begin{tabular}{|c|c|c|c|}
\hline Demographics & Control n (\%) & Intervention $\mathbf{n}(\%)$ & Overall n (\%) \\
\hline Age (years), mean (SD) & 74.8 (6.1) & $74.3(6.3)$ & $74.5(6.2)$ \\
\hline Male gender & $17(54.8)$ & $21(60.0)$ & $38(57.6)$ \\
\hline Caucasian ethnicity & $30(96.8)$ & $32(91.4)$ & 62 (93.9) \\
\hline Married/common law & $22(71.0)$ & $22(62.9)$ & $44(66.7)$ \\
\hline College/university/graduate studies & $19(61.3)$ & $23(65.7)$ & $42(63.6)$ \\
\hline Annual income $>\$ 50000$ & $18(60.0)$ & $17(48.6)$ & $35(53.9)$ \\
\hline Retired & $29(93.6)$ & $29(82.9)$ & $58(87.9)$ \\
\hline Living alone & $10(32.3)$ & $9(25.7)$ & $19(28.8)$ \\
\hline Uses mobility or balance aids & $6(19.4)$ & 4 (11.4) & $10(15.2)$ \\
\hline Wears hearing aids & $18(58.1)$ & $17(48.6)$ & $35(53.0)$ \\
\hline Any falls in the past 3 months & 7 (22.6) & 4 (11.4) & $11(16.7)$ \\
\hline Functional fitness measures & Mean (SD) & Mean (SD) & Mean (SD) \\
\hline Gait speed (m/s) & $1.25(0.20)$ & $1.28(0.25)$ & $1.26(0.23)$ \\
\hline Sit to Stand (30s) & $12.7(3.2)$ & $12.9(2.7)$ & $12.8(2.9)$ \\
\hline Grip Strength $(\mathrm{kg})$ & $68.0(19.4)$ & $71.5(21.6)$ & $69.8(20.5)$ \\
\hline 8-Foot Get Up and Go (s) & $6.4(1.9)$ & $6.1(1.5)$ & $6.3(1.7)$ \\
\hline Sit and Reach $(\mathrm{cm})$ & $-4.6(20.8)$ & $-1.9(20.9)$ & $-3.2(20.8)$ \\
\hline Back Scratch (cm) & $-38.8(21.0)$ & $-39.7(25.5)$ & $-39.2(23.3)$ \\
\hline Balance (s) & $49.3(33.3)$ & $45.9(34.2)$ & $47.5(33.5)$ \\
\hline Psychosocial measures & Median (IQR) & Median (IQR) & Median (IQR) \\
\hline HHIE-25 total & $56(28,68)$ & $38(24,56)$ & $46(26,64)$ \\
\hline Emotional subscale & $30(14,40)$ & $18(14,30)$ & $20(14,32)$ \\
\hline Social subscale & $26(16,32)$ & $18(12,30)$ & $24(14,30)$ \\
\hline de Jong loneliness total & $7(3,10)$ & $6(2,9)$ & $7(3,9)$ \\
\hline Emotional loneliness & $3(1,5)$ & $3(0,5)$ & $3(0,5)$ \\
\hline Social loneliness & $3(2,5)$ & $4(1,5)$ & $3(2,5)$ \\
\hline
\end{tabular}

HHIE, Hearing Handicap Inventory for the Elderly.

\section{Programme evaluation}

Online supplementary file 3 questionnaires were filled out by 24 control group and 33 intervention group participants. The data revealed that a large proportion of both groups agreed or strongly agreed that GAR helped them: better recognise and accept their HL (93\%); be more confident to speak out about their HL in social situations (98\%); and to have a better attitude towards HL (95\%). The majority $(89 \%)$ felt that GAR helped them improve their problem-solving abilities. Intervention group participants reported that they were satisfied with the exercise $(100 \%)$ and reported it was fun $(100 \%)$. The majority $(75 \%)$ indicated they increased their physical activity level outside the programme, and $88 \%$ were confident they would continue with regular exercise after the programme ended. When asked what could improve the programme, participants favoured a larger GAR session room, more emphasis on hearing assistive technologies (eg, telephones) with presentations by commercial companies producing these items, better acoustics in the gym (eg, no fan noise in the background) with an improved sound system and instructors who could speak more slowly and clearly (data not tabled).

\section{DISCUSSION}

In this pilot trial, the feasibility, acceptability and preliminary evidence for the efficacy of a GAR, SHE and exercise intervention for older adults with HL was evaluated. Recruitment and retention rates suggested the study was well received. WTL was found to be feasible and highly acceptable. Strengthening, resistance and coordination exercises coupled with GAR and SHE improved lower extremity strength, gait speed and upper body flexibility. While exercise improved these key functional fitness measures, it provided no additional benefit beyond GAR alone for measures of hearing-related quality of life (HHIE-25) and loneliness. Significant improvements in 
Table 2 Mean change and difference between control and intervention groups for functional fitness and loneliness, adjusted for baseline HHIE-25 score

\begin{tabular}{|c|c|c|c|c|}
\hline & Controlgroup & Intervention group & $\begin{array}{l}\text { Difference } \\
\text { between groups }\end{array}$ & Effect \\
\hline Functional fitness & Mean $\Delta(95 \% \mathrm{Cl})$ & Mean $\Delta(95 \% \mathrm{Cl})$ & Mean $\Delta(95 \% \mathrm{Cl})$ & size \\
\hline Gait speed $(\mathrm{m} / \mathrm{s})$ & 0.07 (0.04 to 0.11$)$ & $0.12(0.09$ to 0.15$)$ & $0.05(0.0 \text { to } 0.09)^{*}$ & 0.57 \\
\hline Sit to Stand (30s) & $0.6(-0.1$ to 1.3$)$ & $1.6(1.0$ to 2.3$)$ & $1.0(0.1 \text { to } 2.0)^{\star}$ & 0.53 \\
\hline 8-Foot Get Up and Go (s) & $-0.5(-0.9$ to 0.2$)$ & $-0.8(-1.1$ to 0.5$)$ & $-0.3(-0.8$ to 0.2$)$ & 0.32 \\
\hline Grip Strength (kg) & $1.3(-0.8$ to 3.5$)$ & 2.8 (0.8 to 4.8$)$ & $1.5(-1.5$ to 4.5$)$ & 0.26 \\
\hline Sit and Reach (cm) & 0.8 (-3.6 to 5.2$)$ & 3.6 (-0.5 to 7.8$)$ & 2.8 (-3.3 to 9.0$)$ & 0.23 \\
\hline Back Scratch (cm) & 0.0 (-2.7 to 2.7$)$ & $4.0(1.4$ to 6.5$)$ & $4.0(0.2 \text { to } 7.7)^{\star}$ & 0.54 \\
\hline Balance (s) & $6.0(0.1$ to 11.9$)$ & $6.8(1.2$ to 12.3$)$ & $0.8(-7.4$ to 9.1$)$ & 0.05 \\
\hline de Jong loneliness total & $-1.5(-2.1$ to 0.9$)$ & $-0.9(-1.4$ to 0.3$)$ & $0.6(-0.2$ to 1.5$)$ & -0.35 \\
\hline Emotional subscale & $-0.9(-1.3$ to 0.5$)$ & $-0.3(-0.7$ to 0.1$)$ & $0.6(0.1 \text { to } 1.2)^{*}$ & -0.54 \\
\hline Social subscale & $-0.6(-1.2$ to 0.1$)$ & $-0.5(-1.0$ to 0.1$)$ & 0.1 (-0.6 to 0.8$)$ & -0.07 \\
\hline
\end{tabular}

${ }^{*} \mathrm{P}<0.05$.

HHIE, Hearing Handicap Inventory for the Elderly; Mean $\Delta$, mean change.

hearing-related quality of life and total and emotional loneliness were found for those attending $\geq 80 \%$ of the GAR sessions and in those with the poorest baseline self-reported hearing-related quality of life. Delivery of GAR by a non-audiologist health provider appeared to be of similar benefit to participants as seen in the literature. To our knowledge, this is the first study to provide an approach to the treatment of HL in older adults that addresses HL-related activity limitations, participation restrictions in addition to physical function (impaired musculoskeletal function) and that showed an improvement in total and emotional loneliness.

\section{Feasibility and acceptability}

Implementation of the WTL proved to be feasible and acceptable to participants. Recruitment strategies, randomisation, study implementation and study completion rates $(88 \%)$ reached the a priori required feasibility goals and more than $95 \%$ of participants found the programme acceptable/highly acceptable.

\section{Functional physical fitness changes}

Preliminary evidence for efficacy of the exercise intervention on physical function was determined using ES in order to help decide on future sample size considerations. ES were calculated on a small sample, therefore need to be interpreted with that in mind. ${ }^{43}$ They suggest that the physical activity and GAR interventions were of some benefit and deserve further investigation in a larger sample.

The WTL exercise intervention was associated with significant improvements in two major functional fitness measures (gait speed; ES 0.57 and $30 \mathrm{~s}$ Sit to Stand; ES 0.53) which have been associated with reduced risk for falls

Table 3 Impact of group and GAR attendance on mean change and difference in change for the HHIE-25 and de Jong loneliness scales $(n=57)$

\begin{tabular}{|c|c|c|c|c|c|c|}
\hline \multirow[b]{2}{*}{ GAR attendance } & \multicolumn{3}{|c|}{ Hearing handicap for the elderly } & \multicolumn{3}{|c|}{ de Jong loneliness and isolation } \\
\hline & $\begin{array}{l}\text { Total score } \\
\text { Mean } \Delta 95 \% \mathrm{Cl}\end{array}$ & $\begin{array}{l}\text { Emotional } \\
\text { subscale } \\
\text { Mean } \Delta 95 \% \mathrm{Cl}\end{array}$ & $\begin{array}{l}\text { Social } \\
\text { subscale } \\
\text { Mean } \Delta 95 \% \mathrm{Cl}\end{array}$ & $\begin{array}{l}\text { Total score } \\
\text { Mean } \Delta 95 \% \mathrm{Cl}\end{array}$ & $\begin{array}{l}\text { Emotion } \\
\text { subscale } \\
\text { Mean } \Delta 95 \% \mathrm{Cl}\end{array}$ & $\begin{array}{l}\text { Social } \\
\text { subscale } \\
\text { Mean } \Delta 95 \% \mathrm{Cl}\end{array}$ \\
\hline \multirow[t]{2}{*}{$<80 \%$ attendance } & 1.3 & -0.1 & 1.4 & 0.2 & 0.2 & 0.0 \\
\hline & -6.0 to 8.6 & -4.3 to 4.1 & -2.3 to 5.1 & -0.6 to 1.0 & -0.4 to 0.8 & -0.7 to 0.7 \\
\hline$\geq 80 \%$ attendance & -9.8 & -6.1 & -3.7 & -1.6 & -0.8 & -0.8 \\
\hline \multirow[t]{2}{*}{ Group difference } & -11.1 & -6.0 & -5.1 & -1.8 & -1.0 & -0.8 \\
\hline & -19.7 to 2.6 & -11.0 to 1.1 & -9.5 to 0.8 & -2.7 to 0.9 & -1.7 to 0.4 & -1.6 to 0.1 \\
\hline$P$ value & 0.012 & 0.018 & 0.022 & $<0.001$ & 0.002 & 0.061 \\
\hline Effect size & 0.76 & 0.71 & 0.69 & 1.16 & 0.96 & 0.58 \\
\hline
\end{tabular}

GAR, group auditory rehabilitation; HHIE, Hearing Handicap Inventory for the Elderly. 
Table 4 Per cent distribution of participant responses for each item on the IOI-Al at follow-up $(n=57)$

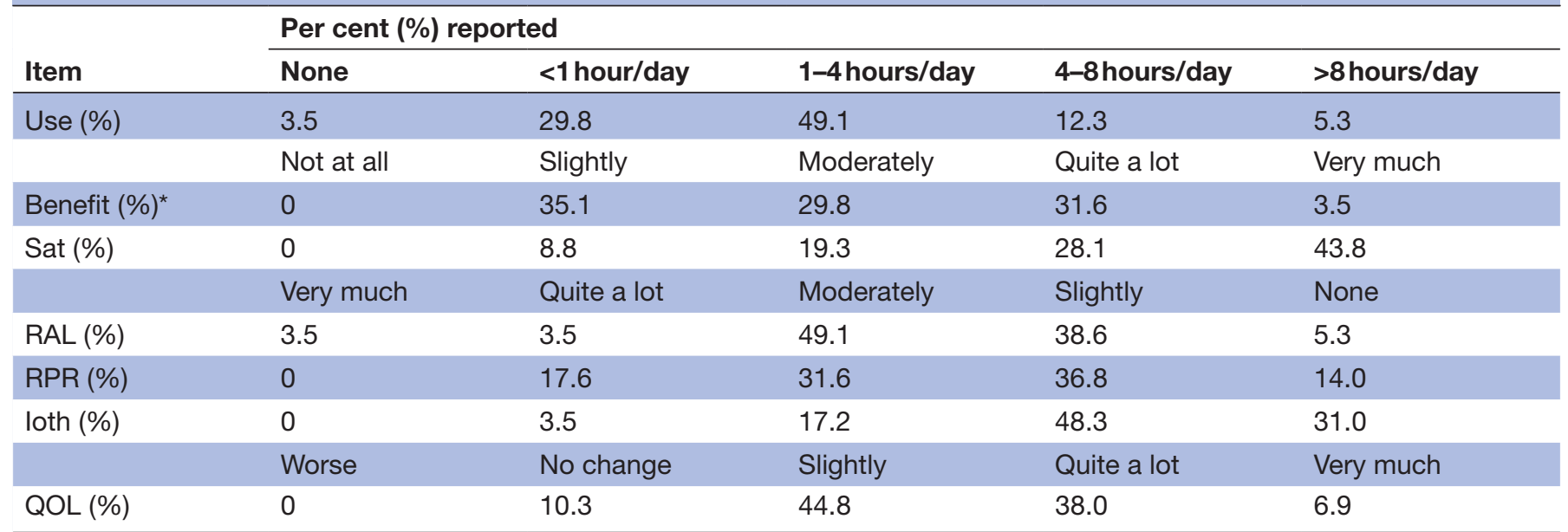

*Statistically significant difference between control and intervention groups (control: not at all=0\%, slightly=26.9\%, moderately=19.2\%, quite a lot $=46.2 \%$, very much $=7.7 \%$; intervention: not at all=0\%, slightly $=41.9 \%$, moderately $=38.7 \%$, quite a lot $=19.4 \%$, very much $=0 \%$; $p=0.040$ ). IOI-AI, international outcomes inventory-alternative interventions; loth, impact on others; QOL, quality of life; RAL, residual activity limitations; RPR, residual participating restrictions; Sat, satisfaction.

and improved maintenance of physical independence. ${ }^{33}$ Adherence to the exercise intervention was excellent and end-of-study evaluations indicated that participants were satisfied with the exercise sessions. Lower body muscle strengthening and improved gait speed are expected to provide long-term benefit as shown in a prospective analysis of longitudinal data from National Health and Nutrition Examination Survey (2003-2006) where adults with at least moderate HL who undertook 2+ sessions/week of muscle strengthening exercises were at a $71 \%$ reduced risk of 7-year all-cause mortality. ${ }^{44}$ However, static (One-Foot Stand) or dynamic (Timed Up and Go) balance was not improved. Furthermore, there was one fall during a fastpaced 'tag'-like exercise where a participant tripped on another participant's foot. While published rates of falls during fall prevention programmes range from $5 \%$ to $25 \%$ (depending on baseline risk for falls) ${ }^{45}$ these findings have important implications for the design of future exercise interventions. Rather than rapid agility/coordination exercises, exercises should include more balance training such as the in-home or facility-based Otago falls prevention exercise programme or tai $\mathrm{chi}^{46}$ which have been shown to reduce falls in the general population of older adults. Incorporation of these focused exercises may be more effective in improving balance in those with HL. The improvement in gait speed and lower extremity muscle strength seen in this pilot trial are encouraging and suggest that such an intervention, if carried on longer term, and which includes more aggressive balance training might be of survival benefit in older adults with HL.

\section{Hearing and health-related quality of life, Ioneliness and} social network

Improvements in loneliness, participation restrictions and activity limitations were related to higher (worse) baseline HHIE-25 (hearing-related quality of life) and higher GAR attendance. Hearing-related quality of life has been found to be an effect modifier in other studies. Using a similar assessment of hearing-related quality of life (Hearing Attitudes to Rehabilitation Questionnaire $)^{39}$ found that higher baseline scores in this measure were also associated with greater benefit from a GAR programme for participation restrictions and activity limitations. The addition of exercise to GAR was of no added benefit for any of the psychosocial outcomes. This was an unexpected finding given the proven benefits of exercise in many of these realms. ${ }^{47}$ It is unknown as to whether poorer hearing-related quality of life supersedes the psychosocial benefits of exercise. Further research is needed in order to understand this interaction.

That GAR attendance had a strong influence on psychosocial outcomes and is consistent with the findings of others who have found that GAR attendance is imperative for optimising the outcomes of GAR. ${ }^{48}$ Our adherence rates of $87 \%$ were comparable to other group-based communication programmes where rates ranged from $56 \%-68 \%{ }^{18}$ to $96 \%{ }^{49}$

The association between untreated HL and loneliness is well known. ${ }^{35}$ Treatment with cochlear implantation ${ }^{17}$ and provision of hearing aids ${ }^{16}$ has been shown to reduce loneliness in older adults with audiometrically measured mild to severe HL. To the authors' knowledge, only one other study has looked at the effect of audiological rehabilitation on loneliness. In this study, ${ }^{50}$ participants were provided with an assistive hearing device (not a hearing aid) and with their communication partners undertook a one-time 1.6-2 hours' GAR session delivered by a trained clinician. Participants were given auditory rehabilitation manuals and workbooks to complete at home. Despite a significant decrease in HHIE scores 
(meaning an improvement in hearing-related quality of life) at 3 months, loneliness (as measured by the University of California Los Angeles Loneliness Scale) increased. In the current study, hearing-related quality of life (HHIE-25) and loneliness (de Jong Loneliness Scale) significantly improved in those with higher GAR attendance, compared with poor attenders, who saw no benefit.

Furthermore, while social isolation was not formally assessed, the COSI results indicate that $42 \%$ of participants increased the amount of their social contact (such as attending more social events, social situations or going out in public) which might be expected to decrease social isolation if maintained over time.

While group or home auditory rehabilitation improves hearing-related quality of life, it appears that GAR may be more conducive than home-based auditory rehabilitation to addressing loneliness.

\section{Health-related quality of life}

Health-related quality of life, as assessed using the SF-36, did not show change by group assignment, GAR attendance or baseline HHIE-25 score. This finding is in agreement with others who also used generic health-related quality of life tools (WHO Disability Assessment Schedule $\mathrm{II}^{49}{ }^{51}: \mathrm{SF}-36^{39}$ ) as a communication programme outcome measure. This was not unexpected given that the content of this questionnaire has little to do with communication and supports our finding that added exercise and health education did affect generic quality of life measures.

\section{GAR evaluation}

Together, the GAR evaluation tools (IOI-AI, COSI and qualitative feedback) suggested that the GAR programme was highly appreciated, benefited and improved self-efficacy of participants. When compared with other studies where communication strategies and psychosocial counselling were key features of GAR, improvement in HHIE-25 (ES=0.69-0.76) was similar to that in one study (ES $0.67-0.78)^{49}$ and slightly greater than that in another $(\mathrm{ES}=0.25){ }^{39}$ Furthermore, outcomes in all domains of the IOI-AI and relevant COSI outcomes compared favourably with these same established communication programmes. ${ }^{38} 3949$ Inclusion of communication strategies and facilitating behaviour change was associated with enhanced self-efficacy, a consistent finding in the literature. $^{52} 53$ As participants gain confidence in managing their HL and achieving their communication and social goals, their hearing-related quality of life improves. ${ }^{49} 51$ These findings are encouraging and add to the emerging evidence, suggesting that with adequate training and resources, a non-audiologist may help build capacity for increased access to effective community-based GAR programming. ${ }^{54-56}$

\section{Strengths and limitations}

This study had several strengths: $57 \%$ of our participants were male. While not uncommon for GAR interventions, it is uncommon to see $>30 \%$ of males participating in community-based exercise programmes. ${ }^{57} 58$ This may simply reflect the higher prevalence of HL in men, or some other factor: qualitative work is underway to examine this.

In this pilot trial, a control group receiving no intervention was not included. This would have made for a more accurate determination the effects of GAR. However, one potential interpretation is that GAR can be effective when given alone or part of a more holistic health behaviour intervention. Second, participants were self-selected which may have introduced a bias favouring positive outcomes. ${ }^{59}$ However, recruitment occurred in the 'real world' community setting and is representative of the population of hearing impaired older adults who have reached the stage of hearing help-seeking. Third, the baseline difference between groups in the baseline HHIE-25 scores is likely due to the small sample size. Although comparisons were reported in terms of relative improvements and not strict comparisons, this should be noted as a potential bias. This study provided only immediate postprogramme results and may have been underpowered to detect changes in the other fitness measures. There is a need for more longitudinal follow-up in a larger sample to determine if the positive changes can be sustained.

Finally, this is the first study to obtain preliminary information on the effectiveness of an exercise intervention to improve functional fitness, and GAR to improve total and emotional loneliness and social support in older adults with self-reported HL. GAR led by non-audiologist shows potential as a way to improve the accessibility of GAR programmes.

Age-related HL is a prevalent, under-recognised and significant disability that when untreated is associated with profound negative downstream effects. This study contributes to emerging evidence of the benefit of providing accessible community-based communication programmes delivered outside the traditional audiology clinical setting. Addition of an exercise component shows at least short-term functional fitness benefits. Further research is needed to determine the long-term benefits of combining communication and exercise programmes on the biopsychosocial domains among older adults with HL.

\section{Implications}

A larger, long-term study is needed to determine the enduring effects of this novel, community-based, holistic intervention in addressing both the negative psychosocial and functional physical effects of HL among older adults. Use of the home or facility-based Otago falls prevention exercise programme (muscle strengthening and a more focused approach to balance training) may be necessary to improve balance in older adults with HL. Face-to-face GAR sessions may be necessary in order to provide additional benefits on loneliness and social support. Provision 
of GAR by students and non-audiologists may improve accessibility of audiological rehabilitation programmes.

\section{Author affiliations}

${ }^{1}$ Medicine, University of British Columbia, Kelowna, British Columbia, Canada

${ }^{2}$ Nexgen Hearing, Kelowna, British Columbia, Canada

${ }^{3}$ Health and Exercise Science, University of British Columbia Okanagan Faculty of Health and Social Development, Kelowna, British Columbia, Canada

${ }^{4}$ School of Health and Exercise Science, University of British Columbia, Kelowna, British Columbia, Canada

${ }^{5}$ Social Work/Sociology, University of British Columbia, Kelowna, British Columbia, Canada

${ }^{6}$ Irving K Barber School of Arts and Social Sciences, University of British Columbia, Kelowna, British Columbia, Canada

Contributors CAJ, PM, JS, JL, KK, MAM, HM, DK and GJ contributed to the study concept and design. CAJ, KK, CVB and MAM contributed to the acquisition of participants and implementation of the study. CAJ, JS and KK performed all the functional fitness testing and other data collection. JS performed the statistical analyses and all authors contributed to the interpretation and writing of the manuscript.

Funding The authors have not declared a specific grant for this research from any funding agency in the public, commercial or not-for-profit sectors.

Competing interests None declared.

Patient consent for publication Not required.

Provenance and peer review Not commissioned; externally peer reviewed.

Data sharing statement All published and unpublished data from this study will be handled as follows: UBC Library Data Management Repository—UBC Library has implemented a robust data management software-Abacus Dataverse-collaborating with Harvard and supporting other BC schools (UNBC, UVic and SFU). The system is designed to manage and preserve data and it is opened to UBC researchers, labs and institutes. UBC will then assign DOls to the UBC Library digital data sets, via our Open Collections portal. DOls increase the further citability and discoverability of UBC research data.

Open access This is an open access article distributed in accordance with the Creative Commons Attribution Non Commercial (CC BY-NC 4.0) license, which permits others to distribute, remix, adapt, build upon this work non-commercially, and license their derivative works on different terms, provided the original work is properly cited, appropriate credit is given, any changes made indicated, and the use is non-commercial. See: http://creativecommons.org/licenses/by-nc/4.0/.

\section{REFERENCES}

1. Lin FR, Niparko JK, Ferrucci L. Hearing loss prevalence in the United States. Arch Intern Med 2011;171:1851-2.

2. Statistics Canada. Hearing Loss of Canadians, 2012 to 2015. Ottawa. 2016.

3. Mick P, Kawachi I, Lin FR. The association between hearing loss and social isolation in older adults. Otolaryngol Head Neck Surg 2014;150:378-84.

4. Strawbridge WJ, Wallhagen MI, Shema SJ, et al. Negative consequences of hearing impairment in old age: a longitudinal analysis. Gerontologist 2000;40:320-6.

5. Davis A, McMahon CM, Pichora-Fuller KM, et al. Aging and hearing health: the life-course approach. Gerontologist 2016;56(Suppl 2):S256-67.

6. Agmon M, Lavie L, Doumas M. The association between hearing loss, postural control, and mobility in older adults: a systematic review. J Am Acad Audiol 2017;28:575-88.

7. Bruce $H$, Lai L, Bherer $L$, et al. The effect of simultaneously and sequentially delivered cognitive and aerobic training on mobility among older adults with hearing loss. Gait Posture 2019;67:262-8.

8. Seeman TE. Health promoting effects of friends and family on health outcomes in older adults. Am J Health Promot 2000;14:362-70.

9. Berkman LF, Glass T, Brissette I, et al. From social integration to health: Durkheim in the new millennium. Soc Sci Med 2000;51:843-57.

10. Leigh-Hunt N, Bagguley D, Bash K, et al. An overview of systematic reviews on the public health consequences of social isolation and loneliness. Public Health 2017;152:157-71.
11. Savikko N, Routasalo P, Tilvis RS, et al. Predictors and subjective causes of loneliness in an aged population. Arch Gerontol Geriatr 2005; $41: 223-33$

12. Rico-Uribe LA, Caballero FF, Martín-María N, et al. Association of loneliness with all-cause mortality: a meta-analysis. PLoS One 2018;13:e0190033.

13. Contrera KJ, Betz J, Genther DJ, et al. Association of hearing impairment and mortality in the national health and nutrition examination survey. JAMA Otolaryngol Head Neck Surg 2015;141:1-6.

14. Millett $P$, Jutras $B$, Noel $G$. Canadian guideline on auditory processing disorder in children and adults: assessment and intervention: canadian interorganizational steering group for audiology and speech-language pathology. 2012.

15. Contrera KJ, Sung YK, Betz J, et al. Change in loneliness after intervention with cochlear implants or hearing aids. Laryngoscope 2017;127:1885-9.

16. Weinstein BE, Sirow LW, Moser S. Relating hearing aid use to social and emotional loneliness in older adults. Am J Audiol 2016;25:54-61.

17. Poissant SF, Beaudoin F, Huang J, et al. Impact of cochlear implantation on speech understanding, depression, and loneliness in the elderly. J Otolaryngol Head Neck Surg 2008;37:488-94.

18. Laplante-Lévesque A, Hickson L, Worrall L. Rehabilitation of older adults with hearing impairment: a critical review. J Aging Health 2010;22:143-53.

19. Hwang J, Wang L, Siever J, et al. Loneliness and social isolation among older adults in a community exercise program: a qualitative study. Aging Ment Health 2018:1-7.

20. Cohen-Mansfield J, Perach R. Interventions for alleviating loneliness among older persons: a critical review. Am J Health Promot 2015;29:e109-e125.

21. Gardiner C, Geldenhuys G, Gott M. Interventions to reduce social isolation and loneliness among older people: an integrative review. Health Soc Care Community 2018;26:147-57.

22. Pitkala KH, Routasalo $\mathrm{P}$, Kautiainen $\mathrm{H}$, et al. Effects of psychosocial group rehabilitation on health, use of health care services, and mortality of older persons suffering from loneliness: a randomised, controlled trial. J Gerontol A Biol Sci Med Sci 2009;64:792-800.

23. McPhee JS, French DP, Jackson D, et al. Physical activity in older age: perspectives for healthy ageing and frailty. Biogerontology 2016;17:567-80.

24. Jutras M, Lambert J, Hwang J, et al. Targeting the psychosocial and functional fitness challenges of older adults with hearing loss: a participatory approach to adaptation of the walk and talk for your life program. Int J Audiol 2018;57:519-28.

25. Lambert J, Ghadry-Tavi R, Knuff K, et al. Targeting functional fitness, hearing and health-related quality of life in older adults with hearing loss: Walk, Talk ' $n$ ' Listen, study protocol for a pilot randomised controlled trial. Trials 2017;18:47.

26. Chang HP, Ho CY, Chou P. The factors associated with a selfperceived hearing handicap in elderly people with hearing impairment--results from a community-based study. Ear Hear 2009;30:576-83.

27. Montano JJ, Preminger JE, Hickson L, et al. A new web-based tool for group audiologic rehabilitation. Am J Audiol 2013;22:332-4.

28. Tiedemann A, Shimada $H$, Sherrington $C$, et al. The comparative ability of eight functional mobility tests for predicting falls in community-dwelling older people. Age Ageing 2008;37:430-5.

29. Steffen TM, Hacker TA, Mollinger L. Age- and gender-related test performance in community-dwelling elderly people: Six-Minute Walk Test, Berg Balance Scale, Timed Up \& Go Test, and gait speeds. Phys Ther 2002;82:128-37.

30. Springer BA, Marin R, Cyhan T, et al. Normative values for the unipedal stance test with eyes open and closed. $J$ Geriatr Phys Ther 2007:30:8-15.

31. Leong DP, Teo KK, Rangarajan S, et al. Prognostic value of grip strength: findings from the Prospective Urban Rural Epidemiology (PURE) study. Lancet 2015;386:266-73.

32. Jones CJ, Rikli RE, Max J, et al. The reliability and validity of a chair sit-and-reach test as a measure of hamstring flexibility in older adults. Res Q Exerc Sport 1998;69:338-43.

33. Rikli RE, Jones CJ. Development and validation of criterionreferenced clinically relevant fitness standards for maintaining physical independence in later years. Gerontologist 2013;53:255-67.

34. Ware JE, Sherbourne CD. The MOS 36-item short-form health survey (SF-36). I. Conceptual framework and item selection. Med Care 1992;30:473-83.

35. de Jong-Gierveld J, Kamphuis F. The development of a rasch-type Ioneliness scale. Appl Psychol Meas 1985;9:289-99.

36. Sherbourne CD, Stewart AL. The MOS social support survey. Soc Sci Med 1991;32:705-14. 
37. Vinkers DJ, Gussekloo J, Stek ML, et al. The 15-item Geriatric Depression Scale (GDS-15) detects changes in depressive symptoms after a major negative life event. The Leiden 85 -plus Study. Int J Geriatr Psychiatry 2004;19:80-4.

38. Hickson L, Worrall L, Scarinci N. Measuring outcomes of a communication program for older people with hearing impairment using the International Outcome Inventory. Int $J$ Audiol 2006;45:238-46.

39. Hickson L, Worrall L, Scarinci N. A randomised controlled trial evaluating the active communication education program for older people with hearing impairment. Ear Hear 2007;28:212-30.

40. Jones CJ, Rikli RE, Beam WC. A 30-s chair-stand test as a measure of lower body strength in community-residing older adults. Res $Q$ Exerc Sport 1999;70:113-9.

41. Whitehead AL, Julious SA, Cooper CL, et al. Estimating the sample size for a pilot randomised trial to minimise the overall trial sample size for the external pilot and main trial for a continuous outcome variable. Stat Methods Med Res 2016;25:1057-73.

42. Cohen J. Statistical power analysis for the behavioral sciences. 2nd edn. Hillsdale, NJ, USA: Lawrence Earlbaum Associates, 1988.

43. Durlak JA. How to select, calculate, and interpret effect sizes. $J$ Pediatr Psychol 2009;34:917-28.

44. Loprinzi PD. Muscle strengthening activities and mortality with considerations by hearing sensitivity. Int J Audiol 2016;55:320-2.

45. Sherrington $C$, Michaleff ZA, Fairhall N, et al. Exercise to prevent falls in older adults: an updated systematic review and meta-analysis. $\mathrm{Br}$ J Sports Med 2017;51:1750-8.

46. Gillespie LD, Robertson MC, Gillespie WJ, et al. Interventions for preventing falls in older people living in the community. Cochrane Database Syst Rev 2012;9:CD007146.

47. Gaz DV, Smith AM. Psychosocial benefits and implications of exercise. Pm R 2012;4:812-7.
48. Chisolm TH, Saunders GH, Frederick MT, et al. Learning to listen again: the role of compliance in auditory training for adults with hearing loss. Am J Audiol 2013;22:339-42.

49. Preminger JE, Yoo JK. Do group audiologic rehabilitation activities influence psychosocial outcomes? Am J Audiol 2010;19:109-25.

50. Nieman CL, Marrone N, Mamo SK, et al. The baltimore HEARS pilot study: an affordable, accessible, community-delivered hearing care intervention. Gerontologist 2016;57:gnw153.

51. Preminger JE, Ziegler $\mathrm{CH}$. Can auditory and visual speech perception be trained within a group setting? Am J Audiol 2008;17:80-97.

52. Smith SL, West RL. The application of self-efficacy principles to audiologic rehabilitation: a tutorial. Am J Audiol 2006;15:46-56.

53. Marrone N, Ingram M, Somoza M, et al. Interventional audiology to address hearing health care disparities: Oyendo Bien Pilot Study. Semin Hear 2017;38:198-211.

54. Sánchez D, Adamovich S, Ingram M, et al. The Potential in preparing community health workers to address hearing loss. J Am Acad Audiol 2017;28:562-74.

55. Nieman CL, Lin FR. Increasing access to hearing rehabilitation for older adults. Curr Opin Otolaryngol Head Neck Surg 2017;25:342-6.

56. Preminger JE. Issues associated with the measurement of psychosocial benefits of group audiologic rehabilitation programs. Trends Amplif 2007:11:113-23.

57. Clare L, Nelis SM, Jones IR, et al. The Agewell trial: a pilot randomised controlled trial of a behaviour change intervention to promote healthy ageing and reduce risk of dementia in later life. BMC Psychiatry 2015;15:25.

58. Gandy R, Bell A, McClelland B, et al. Evaluating the delivery, impact, costs and benefits of an active lives programme for older people living in the community. Prim Health Care Res Dev 2017;18:122-34.

59. Knudsen LV, Oberg M, Nielsen C, et al. Factors influencing help seeking, hearing aid uptake, hearing aid use and satisfaction with hearing aids: a review of the literature. Trends Amplif 2010;14:127-54. 